\title{
VALIDITAS MODUL KERJA DENGAN METODE STUDENT CENTRE LEARNING (SCL) UNTUK MATA KULIAH FISIKA DASAR DI KAMPUS STKIP PGRI SUMATERA BARAT
}

\author{
Helendra $^{1,}$ Abizar $^{2}$ \\ ${ }^{1}$ Pendidikan Fisika STKIP PGRI Sumatera Barat \\ ${ }^{2}$ Pendidikan Biologi STKIP PGRI Sumatera Barat \\ E-mail : helendra@gmail.com \\ http://dx.doi.org/10.22202/jrfes.2015.v1i2.1400
}

\begin{abstract}
A fundamental problem experienced lecturers as fundamental physics lecturer on STKIP PGRI West Sumatera is not the establishment of reciprocal interaction between students and lecturers. Students feel lectures communication in only one direction. This phenomenon could trigger a rapid student bored and tired of learning, so that lectures are not optimal.

A worksheet module that is used for learning activities that follow the pattern of learning coopereative validated and ready to be tested to the student. A learning system developed in this study to design how so students can take an active role in the teaching and learning process. A solution that can be used to solve this problem is to make a module-based method of working with student learning center (SCL). With this method students are required SCL play an active role during the lectures, trained to express opinions that terasahnya ability of students to be able to explore deeper levels of knowledge. One model of learning are the SCL Cooperative Learning. That type of SCL which direction to work in groups
\end{abstract}

Key Word: Worksheet, SCL Method, Cooperative

\begin{abstract}
Abstrak
Suatu permasalahan yang mendasar yang dialami dosen sewaktu mengajar mata kuliah fisika dasar di kampus STKIP PGRI SUMBAR adalah tidak terjalinnya interaksi timbal balik antara mahasiswa dengan dosen tersebut. Mahasiswa merasa komunikasi perkuliahan hanya satu arah. Fenomena inilah yang bisa memicu mahasiswa cepat bosan dan jenuh belajar, sehingga perkuliahan menjadi tidak optimal.

Suatu modul kerja yang digunakan untuk kegiatan pembelajaran yang mengikuti pola coopereative learning tervalidasi dan siap untuk diujicobakan ke mahasiswa. Suatu system pembelajaran yang dikembangkan dalam penelitian ini merancang bagaimana supaya mahasiswa itu bisa ikut berperan aktif dalam proses belajar mengajar itu. Suatu solusi yang bisa digunakan untuk memecahkan permasalahan ini adalah dengan membuatkan suatu modul kerja dengan berbasis metode student centre learning ( SCL ). Dengan metode SCL ini mahasiswa dituntut berperan aktif selama perkuliahan, dilatih untuk mengemukakan pendapat sehingga terasahnya kemampuan mahasiswa untuk bisa mengeksplorasi lebih dalam tingkat pengetahuannya. Salah satu model pembelajaran SCL ini adalah Cooperative Learning. Yaitu tipe SCL yang arahannya untuk bekerja sama dalam kelompok.
\end{abstract}

Kata Kunci : Modul kerja, Metode SCL, Cooperative, 


\section{PENDAHULUAN}

Dalam suatu proses pembelajaran , peranan bahan kerja sangatlah penting karena sangat berpengaruh terhadap tingkat layanan kwalitas belajar mahasiswa. Bahan kerja dirancang agar mahasiswa bisa terarah pada poin poin utama dalam setiap topic pembelajaran. Salah satu bentuk bahan kerja yang bisa digunakan adalah modul kerja.

Dari hasil pengamatan beberapa dosen sebelumnya yang mengajar mata kuliah fisika dasar selama ini yang menggunakan metode teacher centre learning , mahasiswa cendrung cepat bosan, kurang termotivasi dan tidak tertarik untuk mengeksplorasi lebih jauh materi yang diajarkan yang dapat berpotensi menurunkan kemampuan hardskill mahasiswa.

Metode Student Centered Learning (SCL) merupakan metode pembelajaran dengan karakteristik berpusat pada mahasiswa. Metode ini memberikan otonomi dan pembelajaran yang lebih baik pada mahasiswa. Pada SCL, mahasiswa ikut serta dalam menentukan input materi, metode serta waktu pembelajaran dengan disetujui oleh administrator. Dosen berperan sebagai penunjang dan dapat menerima kritik/saran dari para mahasiswanya.

Untuk pengembangan modul kerja ini hanya di batasi oleh metode SCL dengan tipe Cooperative Learning saja. Dimana pada Cooperative learning ini mahasiswanya dibimbing berdiskusi dan bekerja sama dalam kelompok kecil. Modul kerja ini ditargetkan bisa terpakai untuk bahan diskusi dan kerjasama tersebut, dibawah bimbingan dosen sebagai fasilitatornya.

\section{TINJAUAN PUSTAKA}

\section{Pembelajaran dengan Metode Student Centred Learning (SCL)}

Sistem pendidikan tinggi di Indonesia memiliki 4 (empat) tahapan pokok yaitu (1) Masukan (Input); (2). Proses; (3). Keluaran (output); (4). Dampak (outcome). Oleh karena itu untuk menghasilkan lulusan yang berkualitas, pendidikan tinggi harus melakukan proses pembelajaran yang baik. Pembelajaran yang dimaksud adalah terjalinnya interaksi yang baik antara pendidik, peserta didik, dan sumber belajar, didalam lingkungan belajar tertentu. Sehingga dengan mendeskripsikan setiap unsur yang terlibat dalam pembelajaran tersebut dapat ditengarai bahwa system itu adalah suatu ciri pembelajaran yang berpusat pada siswa (student centered learning).

Pada proses belajar mengajar yang menggunakan metode SCL mahasiswa dituntut aktif mengerjakan tugas dan mendiskusikannya dengan dosen sebagai fasilitator. Dengan aktifnya mahasiswa, maka tingkat kreativitas mahasiswa akan terpupuk. Dengan terciptanya kondisi tersebut maka akan timbul dorongan untuk dosen untuk selalu mengembangkan dan menyesuaikan materi kuliahnya dengan perkembangan Ilmu Pengetahuan danTeknologi (IPTEK). Beberapa metode pembelajaran dengan SCL (Dewajani, 2008), yaitu :

- Small Group Discussion

* Simulasi

* Discovery Learning

* Self - Directed Learning

* Cooperative Learning

* Collaborative Learning

* Contextual Instruction 
* Project Base Learning

* Problem Base learning

\section{Metode Student Center Learning Dengan Model Cooperative Learning}

Cooperative learning berasal dari kata cooperative yang artinya mengerjakan sesuatu secara bersama-sama dengan saling membantu satu sama lainnya sebagai satu kelompok atau satu tim. Slavin (1995) mengemuka $\neg$ kan, "In cooperative learning methods, students work together in four member teams to master material initially presented by the teacher". Dari uraian tersebut dapat dikemukakan bahwa cooperative learning adalah suatu model pem-belajaran dimana sistem belajar dan bekerja dalam kelompok-kelompok kecil yang berjumlah 4-6 orang secara kolaboratif sehingga dapat merangsang siswa lebih bergairah dalam belajar.

Cooperative learning merupakan strategi pembelajaran yang banyak menarik perhatian kalangan pengajar. Cooperative learning merupakan strategi pembelajaran yang cukup berhasil pada kelompok-kelompok kecil, di mana pada tiap kelompok tersebut terdiri dari siswasiswa dari berbagai tingkat kemampuan, melakukan berbagai kegiatan belajar untuk meningkatkan pemahaman mereka tentang materi pelajaran yang sedang dipelajari. Setiap anggota kelompok bertanggung jawab untuk tidak hanya belajar apa yang diajarkan tetapi juga untuk membantu rekan rekan belajar, sehingga bersamasama mencapai keberhasilan. Semua Siswa berusaha sampai semua anggota kelompok berhasil memahami dan melengkapinya.

\section{METODOLOGI PENELITIAN}

Kategori untuk penelitian ini bersifat action research . Konsep yang disusun untuk penelitian ini adalah menyerupai kepada penelitian tindakan kelas. Model penelitian tindakan kelas yang banyak digunakan di Indonesia adalah model siklus yang dikemukakan oleh Kemmis dan MacTaggart (Amirin, 2009).

Secara umum tahapan penelitian yang mengikuti model Kemmis dan MacTaggart ini dibagi dalam 5 tahapan utama yaitu : Tahap I Perencanaan (Planning) draf desain modul kerja, Tahap II Tindakan dan Pengamatan (Action \& Observation) penerapan draf desain modul kerja, Tahap III Analisis hasil dan Perencanaan Ulang untuk perbaikan draf desain modul kerja (Reflecting \& Replanning), Tahap IV Tindakan dan Pengamatan (Action \& Observation) penerapan draf desain modul kerja yang telah diperbaiki, Tahap $\mathbf{V}$ Analisis Akhir Penelitian (Reflecting), dimana akan dilakukan perbaikan kembali atas desain modul kerja jika masih dibutuhkan sesuai dengan hasil analisis evaluasi sehingga diperoleh prototipe modul kerja yang paling baik untuk mata kuliah fisika dasar ini.

Proses perancangan dan penyusunan draf desain untuk produk modul kerja memerlukan beberapa langkah yang harus dilawati. Langkah langkah yang harus dilalui itu adalah (plomp, 2010)

a. Tahap "preliminary research"

Pada langkah ini dilakukan peninjauan atau identifikasi masalah, analisis kebutuhan dan analisis konsep atau isi materi, dan pengkajian literatur yang diperlukan dalam pembelajaran.

Selanjutnya, dilakukan analisis terhadap karakter mahasiswa untuk 
menentukan model pengembangan perangkat pembelajaran yang akan digunakan.

b. Fase Perancangan dan Realisasi (prototyping phase)

Pada tahap ini dilakukan penyusunan/perancangan terhadap modul. Rancangan ini merujuk pada panduan pengembangan bahan ajar yang dikeluarkan oleh Dikti (KPT Dikti, 2012). Dalam perancangan bahan ajar melewati beberapa langkah, antara lain : (1) mengkaji kesesuaian materi yang akan disajikan dalam bahan ajar dengan standar kompetensi dan kompetensi dasar yang terdapat dalam kurikulum, (2) menentukan kedalaman materi dan ruang lingkup bahan ajar, (3) menentukan urutan bahan ajar, (4) menentukan jenis perlakuan yang akan diberikan terhadap bahan ajar, (5) menentukan sumber materi pembelajaran.

Setelah tahapan rancang modul selesai, dilakukan formative evaluation yang mencakup self evaluation, expert review, one-to-one and small group .

\section{1) Self Evaluation}

Pada tahap inilah dilakukannya desain modul kerja yang akan dikembangkan. Tahapan ini dilakukan berdasarkan hasil analisis awal atau identifikasi masalah, analisis kebutuhan dan analisis konsep atau isi materi, dan pengkajian literatur yang diperlukan dalam pembelajaran

2) Expert Review

Tahap expert review merupakan tahap untuk pencermatan terhadap modul yang sudah didesain, kemudian dilakukan penilaian dan evaluasi oleh para ahli. Para ahli bertugas menelaah isi, konstruk, dan gaya bahasa dari setiap prototipe. Sanggahan sanggahan srta saran-saran para ahli digunakan untuk merevisi modul yang dikembangkan. Pada tahap ini, sanggahan dan saran dari para ahli (validator) tentang desain yang telah dibuat ditulis pada lembar validasi sebagai bahan revisi dan menyatakan bahwa apakah desain ini telah valid atau masih perlu perbaikan.

Proses validasi dilihat pada aspek design pembelajaran, bertujuan untuk mendapatkan kesesuaian model dan bentuk rancangan dari perangkat pembelajaran yang dikembangkan. Bagian utama yang divalidasi adalah kesesuaian KD, indikator, kebenaran konsep dan bahasa yang digunakan.

3) One-to-one

Pada tahap one-to-one, dilakukan ujicoba desain yang sifatnya person to person kepada mahasiswa dan dosen yang menjadi tester. Hasil dari pelaksanaan ini digunakan untuk merevisi desain yang telah dibuat.

4) Small group

Revisi dari telaah expert dan kesulitan yang dialami pada saat uji coba pada Uji coba pertama dijadikan dasar untuk merevisi modul tersebut, kemudian hasilnya diujicobakan pada small group. Hasil dari pelaksanaan ujicoba ini selanjutnya digunakan untuk revisi sebelum dilakukan ujicoba pada tahap field test. Setelah dilakukan revisi modul berdasarkan saran dan komentar mahasiswa pada small group, diperoleh hasil analisis terhadap modul tersebut.

5) Field Test

Hasil revisi small group selanjutnya diujicobakan ke subjek penelitian. Uji coba dalam hal ini merupakan uji lapangan atau field test. Modul yang telah diujicobakan pada uji lapangan haruslah modul yang telah memenuhi kriteria kualitas yang meliputi validitas, kepraktisan, dan efektivitas. 
c. Fase Penilaian (assessment phase)

Tahapan ini berfungsi untuk mengetahui apakah modul dapat digunakan untuk mencapai tujuan yang efektif dalam meningkatkan kualitas dan prestasi belajar mahasiswa atau belum.

\section{HASIL DAN ANALISA}

Mengacu kepada hasil investigasi awal yang dilakukan terhadap mahasiswa maka dilakukan perancangan modul kerja dengan pola Student Centre Learning menggunakan model Cooperative Learning. Berikut ini diuraikan karakteristik handout fisika dasar menggunakan pola Student Centre Learning dengan model Cooperative Learning tersebut..

a. Modul kerja yang disusun diawali dengan deskripsi umum bahasan. Pada deskripsi umum ini disampaikan apa hal hal yang berkaitan dengan bahasan dengan kehidupan sehari hari. Dalam deskripsi awal ini mahasiswa diarahkan kepada kejadian kejadian dikeseharian yang berhubungan dengan topik yang akan dibahas. Salah satu bahasan yang ada di fisika dasar adalah tentang Momentum dan Impuls. Peristiwa tabrakan bisa dijadikan sebagai contoh untuk bahasan momentum ini. Berikut merupakan contoh halaman deskripsi awal dari modul kerja ini yaitu

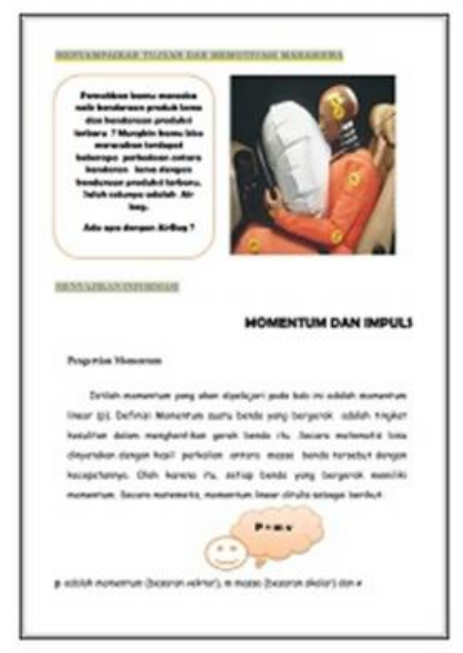

b. Penyampaian materi sesuai dengan tahapan tahapan cooperative learning

Batang tubuh dari modul kerja ini disusun berdasarkan fase-fase dalam syntak model Cooperative Learning. Fasefase ini meliputi penyampaian tujuan, menyajikan informasi, membuatkan kelompok belajar, membantu kerja kelompok, mengevaluasi dan terakhir memberikan pengakuan. Oleh karena itu, pendisainan modul kerja ini penuh dengan contoh soal yang akan dikerjakan secara berkelompok. Contoh potongan lembaran modul kerja ini yang menyangkut bagian ini adalah 

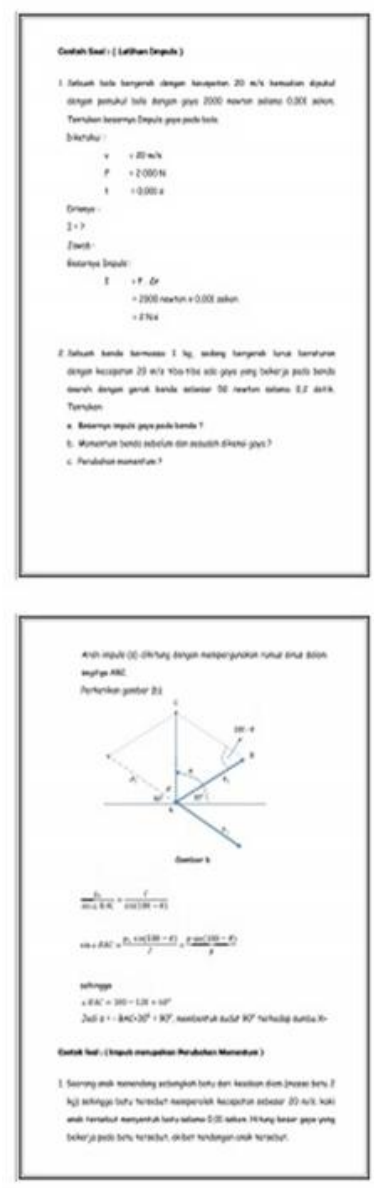

Untuk mencapai tujuan mahasiswa yang aktiv serta cooperatif dalam mengikuti perkuliahan, maka modul kerja ini dilengkapi dengan lembar kerja yang berisi soal soal yang harus dikerjakan oleh mahasiswa . Lembaran inilah bagian yang utama pada modul kerja ini. Contoh potongan lembaran tresebut disajikan seperti berikut :

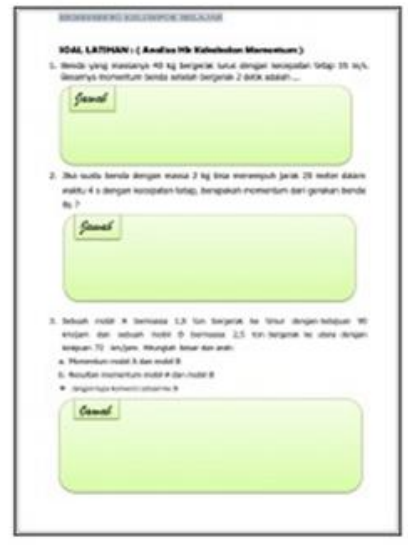

Modul kerja ini sudah divalidasi oleh 2 orang validator. Modul kerja ini dinyatakan valid oleh validator setelah dilakukan revisi hasil validasi pertama. Perbaikan dilakukan pada tampilan modul. Berdasarkan hasil validasi pertama, validator menyarankan agar dituliskan keterangan gambar, kemudian tanda baca yang benar, tampilan handout masih cenderung monoton dan kurang menarik sehingga perlu dibuat lebih menarik lagi. Salah satu caranya mengikuti saran dari validator dan memberikan warna yang cerah pada modul kerja ini.

Pengadaan modul kerja sangat menunjang terlaksananya proses pembelajaran yang optimal dan lebih terarah. Modul kerja yang digunakan harus valid sehingga layak digunakan dalam proses pembelajaran. Pada penelitian ini, validasi dilakukan dari segi isi, konstruk, dan bahasa. Dengan demikian, modul kerja yang digunakan dalam kegiatan pembelajaran telah valid. Sebelum melakukan perancangan handout terlebih dahulu dilakukan analisis konsep, analisis karakteristik mahasiswa, dan kajian terhadap literatur yang ada.

Validasi modul kerja ini dilakukan sebanyak dua kali. Pada validasi pertama ditemukan beberapa kekurangan dari produk yang dirancang. Kemudian, produk tersebut direvisi sesuai saran dari validator. Hasil revisi ini kemudian divalidasi kembali sehingga didapatkan modul kerja dengan kategori sangat valid. Berdasarkan hasil validasi dengan nilai maksimal 100, diperoleh nilai 83,52 dari validator pertama dan nilai 81,17 dari validator kedua. Modul ini dinyatakan sangat valid oleh validator karena modul kerja yang disusun ini telah sesuai dengan pola cooperative learning. 
Dengan menggunakan hitungan :

$\boldsymbol{V}=\frac{\boldsymbol{f}}{\boldsymbol{n}} \times \mathbf{1 0 0}$

dimana $f=$ skor yang didapat

$n=$ skore maksimal

didapat Nilai :

\begin{tabular}{|l|l|l|l|}
\hline VALIDATOR & $\begin{array}{c}\text { Nilai } \\
\text { Awal }\end{array}$ & $\begin{array}{l}\text { FINAL } \\
\text { SCORE }\end{array}$ & STATUS \\
\hline Validator 1 & 69,32 & 83,52 & $\begin{array}{l}\text { Sangat } \\
\text { Valid }\end{array}$ \\
\hline Validator 2 & 72,94 & 81,17 & $\begin{array}{l}\text { Sangat } \\
\text { Valid }\end{array}$ \\
\hline
\end{tabular}

Berdasarkan nilai validasi yang terhitung, maka desain modul kerja ini berstatus

\section{SANGAT VALID}

Dengan begitu modul kerja ini sudah bisa di bawakan ke perkuliahan fisika dasar untuk diamati tingkat praktikalitas dan efektifitasnya pada mahasiswa. Seiring berjalan waktu, desain modul ini akan terus diperbaiki dan lebih disempurnakan.

\section{KESIMPULAN}

Pola belajar menggunakan metode Student Centre Learning yang secara tidak langsung sangat dekat dengan kurikulum 2013 merupakan suatu metode pengajaran yang menitik-beratkan proses belajar mengajar ke-keaktivan peserta didiknya. Dan dosen atau guru hanya berperan sebagai fasilitator. Untuk itu mahasiswa sebagai peserta didik harus dilengkapi dengan sarana atau panduan yang bisa mereka gunakan untuk belajar. Modul kerja yang dirancang dengan bahasa yang sederhana akan bisa membantu para mahasiswa dalam memahami pelajaran. Desain modul kerja dengan tampilan yang menarik serta diiringi dengan latihan latihan terbimbing akan bisa mengurangi rasa jenuh bagi mahasiswa yang menggunakannya.
Berdasarkan hasil validasi bisa dilihat bahwa desain modul kerja ini sudah cukup praktis dan terintegrasi antara ringkasan materi dengan soal - soal latihan, yang mana hal ini akan sangat membantu untuk mahasiswa yang cepat bosan jika mendengar perkuliahan dengan metode ceramah.

\section{DAFTAR PUSTAKA}

Dewajani, Sylvi. 2008, Bahan pelatihan Kurikulum Berbasis Kompetensi (KBK) dan pemelajaran student centred Learning (SCL), Tim KBK Dikti.

Amirin, Tatang M. (2009). Classroom action research (penelitian tindakan kelas), diunduh di http://www.tatangmanguny.files. wordpress.com/2009/05/kemmismctaggart-ar-cycles1.gif, Sabtu, 14 April 2012

Plomp, Tjeerd. (2010). An Introduction to Educational Design Research. Enschede: University of Twente

Arifin, Samsul. 2010, P3AI-ITS, metode pembelajaran Student Centered Learning, diunduh dari http://abdulkadirsyam.wordpress. com/2010/03/12/metode-belajarstudent-center-learning-scl/

Arifin, Syamsul. 2010, Memahami KBK_SCL dan implementasinya. P3AI-ITS, diunduh dari http://www.vilila.com/2010/10/me mahami-kbk-scl-danimplementasinya.html 
Ridwan, 2006. Belajar mudah penelitian untuk dosen, karyawan dan peneliti muda. Bandung, Alfabeta

Buku Panduan Pelaksanaan Student Centered Learning (SCL) dan Student Teacher Aesthethic RoleSharing (STAR), Pusat Pengembangan Pendidikan, Universitas Gajah Mada, 2010

Buku Panduan Pengembangan KBK Pendidikan Tinggi, Direktorat Akademik, Direktorat Jenderal Pendididkan Tinggi, 2008.

Buku Panduan Penyusunan Kurikulum Pendidikan Tinggi (KPT), Direktoran Pembelajaran dan Kemahasiswaan, Direktorat Jenderal Pendididkan Tinggi, 2012

Belawati, Tian ( 2003 ). Pengembangan bahan ajar, Universitas Terbuka
Media Pendidikan Indonesia (2012), Desain PTK Model Kemmis \& McTaggart, Copyright : www.medukasi.web.id, diunduh Sabtu, 14 April 2012, di http://www.medukasi.web.id/2012/04/desain-ptkmodel-kemmis-mctaggart.html

Kepmen No 232/U/2000 Tentang Pedoman Penyusunan Kurikulum Pendidikan Tinggi dan Penilaian Hasil Belajar Mahasiswa

Perpres No. 8 Tahun 2012 tentang Kerangka Kualifikasi Nasional Indonesia (KKNI)

Rahmat, 2011, Lokakarya Pengembangan Kurikulum Berbasis Kompetensi, Universitas Diponegoro, http://eprints.undip.ac.id/28581/ 